RUNNING HEAD: EVALUATION OF A PSYCHOTHERAPY SUPERVISION

\title{
TRAINING COURSE
}

Supervisor trainees' and their supervisors’ perceptions of attainment of knowledge and skills.

An empirical evaluation of a psychotherapy supervisor training programme.

Eva C. Sundin, $\mathrm{PhD}^{1}$, Marie-Louise Ögren, $\mathrm{PhD}^{2}$, Siv Boalt Boëthius, $\mathrm{PhD}^{3}$

${ }^{1}$ the Division of Psychology, Nottingham Trent University, England

${ }^{2}$ the Department of Psychology, Stockholm University, Sweden

${ }^{3}$ the Department of Education, Stockholm University, Stockholm, Sweden

Word count (exc. figures/tables): 7,764

*Requests for reprints should be addressed to Eva Sundin, Division of Psychology, Nottingham Trent University, Burton Street, Nottingham, NG1 4BU, England e-mail: eva.sundin@ntu.ac.uk 
Supervisor Trainees’ and Their Supervisors’ Perceptions of Attainment of Knowledge and

Skills. An Empirical Evaluation of a Psychotherapy Supervisor Training Programme.

Objectives This study aimed to evaluate the success of a two-year, part-time training programme for psychotherapy supervisors. A second aim was to examine factors that might contribute to perceived knowledge and skills attainment during the training course.

Design This is a naturalistic, longitudinal study where several measures are used to examine group process and outcome.

Methods Supervisor trainees' $(n=21)$ and their facilitators' $(n=6)$ ratings of learning (knowledge and skills), relations to the supervisor and supervision group, usage of the group, and supervisor style were completed at three time points.

Results The findings suggested that both trainees and their supervisors perceived that the trainees attained a substantial amount of knowledge and skills during the course. In accordance with the literature and expectations, the regression analysis suggested a strong negative association between a strong focus on group processes in the initial and middle phases of the training and perceived knowledge and skills attainment in the final phase of the training. The expected, positive role of relations among trainees in the supervision group in the first half of the training and perceived knowledge and skills attainment in the final part of the training was obtained, whilst the hypothesized significance of the relationship between trainee and supervisor did not receive support.

Conclusions The supervisory course seemed to provide a training that allowed trainees to attain knowledge and skills that are necessary for psychotherapy supervisors. The results of this pilot study also emphasize the need of more research on learning in the context of group supervision in psychotherapy.

Key words: psychotherapy supervisor programme, trainee, supervisor, knowledge and skills, actual and ideal usage of the group, supervisor style 
During recent decades, psychotherapy supervision has been considered a crucial psychotherapy training method for beginning psychotherapists, and in consequence it has received considerable attention (e.g., Ekstein \& Wallerstein, 1972; Holloway \& Neufeldt, 1995; Jakubowski-Spector, Dustin, \& George, 1971; Linehan, 1980; Rice, 1980). Up until now, this attention has mainly been directed towards the training of beginning psychotherapists whereas the training of the supervisors has been neglected (Falender, Cornish, Goodyear, Hatcher, Kaslow et al., 2004; Milne \& James, 2002; Russell \& Petrie, 1994; Watkins, 1998; Whitman, Ryan, \& Rubenstein, 2001).

When psychotherapy supervision is regarded as a professional specialty of its own, the need of formal training to become a supervisor tends to be emphasized, despite the lack of empirical evidence. In November 2002, a working conference, The Competencies Conference: Future Directions in Education and Credentialing in Professional Psychology, was held in Scottsdale, Arizona, where supervision along with seven more competency domains were discussed by representatives from the United States and Canada. The general consensus of the supervision workgroup (Falender et al., 2004) was that "supervision (is) one of psychology’s core competencies” (p. 773)...”and as such it should be developed through systematic graduate education and clinical training” (p. 774).

The literature describes a number of training courses in psychotherapy supervision offered in various countries (Barnett, 1998; Bernard, 1994; Frayn, 1991; Neufeldt, 1994; Whitman et al., 2001). However, there are several limitations in this literature: few systematic evaluations of supervision programmes have been presented (Milne \& James, 2002); and comparisons of two courses are almost nonexistent, which probably is partly due to the fact that the courses vary widely in terms of length, format, content, who teaches the course, and for whom the course is designed (Whitman et al., 2001). 
A further difficulty associated with the diversity of models for psychotherapy supervision is that it hinders the formulation of general criteria for what is 'good' supervision, and in consequence the development of clear expectations for accreditation and licensure regarding supervision competencies (Falender et al., 2004). In Sweden, the first state-funded supervisor training programme was arranged in 1974 (Janson, 1975). Today, having completed a twoyear psychotherapy supervisor programme is a prerequisite for working as a supervisor, and this programme is offered at most Swedish educational institutions that arrange psychotherapy courses. The training programme aims to provide participants with a comprehensive introduction to the role of a psychotherapist supervisor. To fulfil this aim, the course structure is developed around didactic seminars in combination with supervised practice.

Up until recently, no systematic empirical study of the psychotherapy supervision programmes in Sweden had been published. A first attempt to change this state of affairs was a qualitative study of supervisor trainees’ and supervisors' experiences of psychotherapy supervision in group (Ögren, Boalt Boëthius, \& Sundin, 2007). In that study, trainees and their supervisors reported that they believed that group supervision is suitable on an advanced training level, given that the trainees already had received individual supervision at an earlier stage of their clinical training. The present pilot study aimed to evaluate the success of the training programme with self-report data from 21 trainees and their supervisors. Following Milne and James’ (2002) recommendation, we used data from four of the multiple dimensions of the supervision process: perceived attainment of knowledge and skills, relation to the supervisor and supervision group, usage of the group as a teaching tool, and supervisor style.

Both the present and previous studies of group supervision for beginning supervisors (Ögren et al., in press) are part of a research project which investigates clinical training in an academic context (the GUT project). Another strand of work within the GUT project is represented by a number of studies that examine group supervision for novice 
psychotherapists in training (Ögren \& Jonsson, 2003; Ögren, Jonsson, \& Sundin, 2005; Ögren \& Sundin, 2005; Sundin \& Ögren, 2006). The general aim of the GUT project is to evaluate the clinical training that becoming psychotherapists and psychotherapy supervisors receive as part of their training in five Swedish universities and university affiliated institutions.

A persistent problem in the area of psychotherapy supervision research has been the slow development of psychometrically sound instruments. Two decades ago, Worthington (1987) reported that most quantitative studies of psychotherapy supervision use instruments that are used by just a few other researchers. With few exceptions, this problem seems to persist (but see the Supervisory Working Alliance Inventory, Efstation, Patton, \& Kardash, 1990; the Supervisory Styles Inventory, Friedlander \& Ward, 1984). Since these instruments, along with other available self-rating scales were deemed inadequate for the purposes of studying group supervision; or for the specific research questions that were studied in the GUT project, a set of questionnaires were developed. Some of these are used in the present study to measure perception of 1) knowledge and skills attained in group supervision and relations with the supervisor and supervision group; 2) usage of the group as a teaching tool; 3) supervisor style. In this study, as in previous studies (Boalt Boëthius, Sundin, \& Ögren, 2006; Ögren et al., 2005, Ögren \& Sundin, 2005; Sundin \& Ögren, 2006) of beginning psychotherapists, trainee ratings of perceived acquired knowledge and skills were interpreted as an indicator of trainee experience of mastering the role of a beginning psychotherapist/ supervisor, not as an objective assessment of acquired competence. The relationship between perceived acquired competence and some of the variables that are viewed as important in the supervision literature will be studied: trainee and supervisor ratings of relations with supervisor and supervision group, actual and ideal usage of the group, and supervisor style.

Although the instrument that was developed to measure knowledge attainment and relations to supervisor and group peers aimed to be used in a group setting, previous research on, e. g., 
working alliance in individual supervision was reviewed, and when possible, taken into account. A literature search was undertaken to find out if previous research had used a measure of the usage of the group as a didactic tool in group supervision. No such instrument was found and a new rating scale was developed from Proctor and Inskipp’s theory (2001). Proctor and Inskipp (2001) suggested that there are at least three ways of using the group in a training context. These three pedagogic designs differ from each other in terms of the extent to which group interactions are taken into account in the supervisory learning process. At one end of the continuum, we find authoritative supervision, which is characterized by a dyadic relationship between the facilitator and each of the trainees in the presence of the supervision group. The authors' named this supervision in the group. At the other end, we find cooperative supervision, which is supervision by the group. Here, group interactions are important teaching tools, and trainees are encouraged to share responsibility for the supervision tasks. In-between falls participative supervision, where the facilitator encourages the individual trainee's active participation in the supervision. To our knowledge, the relationship between knowledge attainment and how the group is used as a teaching tool in group supervision in a psychotherapy supervisor course has not been examined as yet.

Results from a previous study of group supervision for beginning psychotherapists suggested that differences in supervisor style were related to supervisees' experience of attained knowledge and skills (Ögren et al., 2005), however, that study did not examine the characteristics of different supervisor styles. In the present study, a preliminary investigation of the relation between specific supervisor styles and perceived attained knowledge and skills was performed. As discussed by Friedlander and Ward (1984) several attempts to delineate a set of supervisor styles have been undertaken. Many of these describe the supervisor's attitude in terms of roles, “extrapolated from a social context other than supervision” (p. 541), e. g., that of lecturing, counselling, and teaching. In contrast, Friedlander and Ward (1984), and 
Ladany and Lehrman-Waterman (1999), defined supervisor style as the supervisor's approaches and responses to trainees. In this study, the latter definition was used. Given the potential importance of supervisor style, it is surprising to find that relatively little effort has been devoted to developing measures of the concept.

One of few measures of supervisor style that has been used in published studies is the Supervisory Styles Inventory (SSI) (Friedlander \& Ward, 1984). Although support for the SSI’s reliability and validity has been reported (e.g., Efstation, Patton, \& Kardash, 1990; Friedlander \& Ward, 1984; Herbert, Ward, \& Hemlick, 1995; Ladany \& Lehrman-Waterman, 1999; Usher \& Borders, 1993), we believe that problems inherent in the instrument warrant development of an alternative measure of supervisor style. One problem is that only positive styles are measured with the SSI, which may affect the supervisee’s or supervisor's conscious efforts to evaluate his/her perceptions. Second, several studies have obtained moderate to strong correlations among the three subscales (Herbert et al., 1995; Ladany, Walker, \& Melincoff, 2001; Steward, Breland, \& Neil, 2001), which suggests that the three subscales only measure one style.

In a more positive vein, it could be argued that the number of measures that are in usage within a domain can be too limited, which can slow down the theoretical development (see, e. g., the discussion on the many measures of intelligence by Sternberg and colleagues, 2006). The fact that only a small number of measures have been developed for usage in group supervision (Prieto, 1996) is therefore taken to support the development of a new measure of psychotherapy supervisor style. In this study a pilot version of this new measure is used.

The objective of this study was to perform a pilot evaluation of a psychotherapy supervisor training programme using trainees' and their supervisors’ perceptions of attainment of knowledge and skills. Secondly, the study aimed to examine factors that might contribute to perceived knowledge and skills attainment. The second aim used regression analysis to 
examine the relationship between attainment of knowledge and usage of the group as a teaching tool, relations with supervisor and supervision group, and supervisor style. Based on the literature on the critical importance of the working alliance in individual supervision (e. g., Efstation et al., 1990) we expected to find that the relationship between trainee and facilitator, and the relationships among the trainees in the first part of the course would be related to perceived attainment of knowledge and skill in the latter part of the course. Second, following Proctor and Inskipp’s theory (2001), we expected to find a positive association between a sparse usage of the group as a teaching tool in the initial part of supervision.

\section{Method}

\section{Design}

A naturalistic, longitudinal design was used where several measures analyzed group process and outcome.

\section{Participants}

Participants were 21 trainees who attended a training programme for psychotherapy supervisors at two different university affiliated institutions, the Erica Foundation and St. Lukas Institute, both situated in Stockholm, Sweden, and their 6 group supervisors. The dataset represents the population of trainees and supervisors who worked in the programme during 2002-2003 and 2004-2005 respectively. There were no missing values.

About two thirds (71\%) of the trainees were female. Their age ranged from 46 to 56 years, average age was 49.6 years ( $\mathrm{SD}=3.6)$. All trainees were authorized psychotherapists with a minimum of three years experience of psychotherapeutic work after authorization. The trainees had had a minimum of 250 supervision sessions. They had received at least 125 individual sessions of personal psychotherapy. They were admitted to the training course based on high school grades, clinical experience, and individual interviews. 
Six supervisors had one supervision group each. Half of the supervisors were male and half of them were female. All supervisors were highly experienced, authorized clinical psychologists who had completed a two-year training programme in psychotherapy supervision. The average supervisory experience was 15 years.

All participants had a psychodynamic orientation. Both the supervisees and the supervisors were representative in terms of age, gender and work experience, of authorized psychotherapists in Sweden. All participants were Caucasian.

\section{The training programme}

At both institutions, the supervisor programme was a two-year, part-time training course with a psychodynamic orientation. The aims and content of the programme, evaluation procedures and time frames for the trainees' supervisory work were clearly defined. The course structure was built around regular (two hours/week) theoretical seminars and group supervision.

The seminars aimed at developing an understanding of the formulation of the supervision contract. Different approaches to doing supervision (client-, process- and relation-oriented supervision) were highlighted. The need for an extended contract for group supervision was discussed, together with different ways of using the group as a teaching tool in group supervision. Ethical and legal aspects of the supervisor's role and responsibilities were examined, and the critical importance of research in the area of psychotherapy supervision was highlighted. The prospective role as a teacher in psychotherapy was also discussed.

The group supervision aimed at increasing the trainees' understanding of the supervision process, enhance their reflective learning process, identify and address their learning styles, and approach potential learning dilemma. For example, trainees received training in developing skills to assess strengths and weaknesses of the supervised psychotherapist. Specifically, the supervisee should acquire: 
- a new and complementary identity as supervisor by changing the focus from being a therapist (the psychotherapy process) to a supervisor (the learning process)

- $\quad$ knowledge and skills about teaching and supervising

- $\quad$ knowledge and experience of small group processes

The supervision was conducted with a frequency of two hours every week; a total of 140 hours. Each group comprised a supervisor and 3 or 4 trainees. Each trainee selected a psychotherapist or a psychotherapy group (comprising of between two and four supervisees) who would receive supervision on an individual therapy by the trainee. Before the supervisor trainee began his/her supervisory practice, the selection of psychotherapy supervisee/s was discussed with the supervisor and group peers on the training programme.

The supervision groups were put together by the programme’s administrative management (the programme director, course coordinator). The supervisors participated in regular meetings arranged by the programme administration, where various events and situations that arose during supervision were discussed. Evaluations of both individual students and supervision groups were made continually and discussed during these meetings.

\section{Measurement procedures and instruments}

Measurement procedures

Quantitative data from questionnaires developed within the GUT project (for details, see Ögren \& Sundin, 2004) were used. These questionnaires were constructed in two versions to assess the supervisee’s and supervisor's perceptions of 1) the supervisee’s attained psychotherapy knowledge and skills, relation to the supervisor and the supervision group; 2) usage of the supervisory group as a teaching tool, and 3) supervisor style. All ratings were made on a 5-point scale ranging from (1) 'to a very little extent' to (5) 'to a very large extent'. 
Each supervisee $(\mathrm{n}=21)$, appraised his/her knowledge and skills attainment, relations to supervisor and peers, usage of the group as a teaching tool, and the supervisor's style. The supervisors assessed each of his/her supervisee’s knowledge and skills attainment and relations to supervisor and peers $(n=21$ ratings). The six supervisors also rated the style that s/he perceived that s/he had used in the supervision, and usage of the group as a teaching tool. Data were collected at three time points: after 6, 12, and 18 months of supervised practice.

\section{Instruments}

The development of a questionnaire to evaluate the supervisee’s psychotherapy knowledge and skills, relation to the supervisor and relation to the group used the following steps: 1) the authors created a set of possible items based on literature studies, clinical and supervisory experience, and previous research in the field; 2) a series of seminars was arranged in which the authors along with experienced psychotherapy supervisors participated. The seminars resulted in agreement on items that should be kept, sometimes after reformulation, and the creation of new items. The following criteria for content validity were used as guidelines: relevance; clarity; simplicity; ambiguity. 3) A pilot study was done where a group of supervisees $(n=100)$ completed the questionnaire. The results of the pilot study suggested that the questionnaire was acceptable for use in further studies.

\section{Evaluation of Knowledge Attainment and Relations in Group Supervision (EKARGS)}

The EKARGS is a 20 item scale that measures perceptions of knowledge and skills that the trainee attained during supervision, and the trainees relation to the facilitator and the supervision group. In a previous study (Ögren \& Sundin, 2005) three subscales were developed from factor analyzing the items in the EKARGS. The first factor consisted of 7 items (e. g., “I was able to integrate theoretical knowledge and practical work”) and was 
named Knowledge attainment. Both the second and the third subscale consisted of 5 items; the second subscale was named Relation to the supervisor (e.g., "I found it stimulating to receive supervision”), and the third subscale was named Relation to the supervision group (e.g., "I have been able to contribute to the co-operation in the supervision group”). The three factors had acceptable internal consistencies $(\mathrm{a}=.82, \mathrm{a}=.88$, and $\mathrm{a}=.87$ respectively).

\section{Usage of the Supervisory Group Scale}

To measure experiences of the usage of the group as a teaching tool, the Usage of the Supervisory Group Scale (USGS) was developed. The eight items of the USGS was developed from Proctor and Inskipp’s theory (2001): four items measure how an individual supervisee/supervisor experience that the group actually was used and the remaining four items measure how an individual wished that the group had been used as a tool. Item 1A (actual). The group supervision provided an environment for individual supervision in a group setting.

Item $1 B$ (wish). I wish that the group supervision had provided an environment for individual supervision in a group setting.

Item $2 \mathrm{~A}$ (actual). Group processes that may impede the learning were recognized and clarified in the supervision.

Item $2 B$ (wish). I wish that group processes that may have impeded the learning had been recognized and clarified in the supervision.

Item $3 A$ (actual). Group interactions were utilized as a means for showing us/the supervisees how we/they can learn from each other.

Item $3 B$ (wish). I wish that group interactions had been used as a means for showing us/the supervisees how we/they could learn from each other. 
Item 4A (actual). Group interactions were used as a means for enhancing our/the supervisees' understanding of the interaction between client's issues and supervision.

Item $4 B$ (wish). I wish that group interactions had been used as a means for enhancing our/the supervisees' understanding of the interaction between client's issues and supervision.

In the present study, we constructed an index measuring the extent to which the group was used as a teaching tool from the four items that measured actual and ideal usage of the group respectively. The first index was computed by adding the three items that denoted that the group actually was used as a teaching tool and subtracting the item that denoted that the group supervision actually provided an environment for individual supervision in a group setting. The same procedure was used to compute an index for the items that measured the ideal usage of the group. The scores for the indices ranged from -5 to 15 . The index for actual usage of the group as a teaching tool had acceptable alphas at the three measurement points $(\mathrm{a}=.73$, $.78, .76)$ while the index for ideal usage of the group had rather low alphas $(\mathrm{a}=.67, .53, .58)$.

\section{Supervisor Style Questionnaire}

A first step to develop a new measure of supervisor style was taken with twelve items designed to measure to what extent the supervisor uses a style that is Supportive, Active, Exploring, Engaging, Consultative, Theoretical, Structured, Permissive, Sensitive, Critical, and Directive. The rationale behind and development of the Supervisor Style Questionnaire are described in a previous study (Boalt Boëthius, Sundin, \& Ögren, 2006). In that study, the data were analyzed with factor analysis, and three subscales were created based on the factors. The internal consistencies were acceptable $(\mathrm{a}=.84, .61$, and .65 respectively), considering the fact that each subscale only contained 4 items at the time of the data collection for that study. The subscales were named Supportive style (exploring, invested, empathic, accepting); 
Demanding style (confronting, critical, non-supportive, theoretical); and Decisive style (consultative, directive, active, structured).

\section{Results}

The objective of this study; a pilot evaluation of a psychotherapy supervisor training programme, was tested with a General Linear Model Repeated Measures (GLM) procedure, based on trainee and supervisor ratings of knowledge and skills from three different time points (6 months; 12 months; and 18 months). The second study aim; an exploration of factors that might contribute to perceived knowledge and skills attainment used simple regression analysis with backward elimination. All analyses were performed using SPSS version 14 (SPSS, Inc., Chicago IL).

\section{Changes over time in perceived supervisory knowledge and skills}

The GLM suggested that there was a significant change in knowledge and skills ratings over time, $\underline{\mathrm{f}}(2,39)=27.293, \mathrm{p}<.001$, partial Eta squared $=.583$. Observed power was 1 . The interaction between knowledge and skills ratings and group (trainee/supervisor) was not significant (it should be noted that each of the 6 supervisors rated their supervisees individually, thus there were 21 supervisor ratings). See table 1.

\section{Table 1 about here}

As is illustrated in table 1 , there is a small but substantial change over time in trainee and supervisor ratings of knowledge and skills attainment. In contrast, the difference between the trainees and their supervisors is insignificant. 
The first simple regression analysis tested how much of the variance in the EKARGS:

Knowledge and skills attainment scored at 18 months that was accounted for by the following scales scored at 6 months: EKARGS Knowledge and skills attainment scores, EKARGS Relations with the supervisor and EKARGS Relationship with the supervision group; USGS Actual use of the group and USGS Ideal use of the group; and the three SSQ subscales: Supportive style, Demanding style, and Decisive style. To examine possible differences between trainees and facilitator, and the two institutions these variables were entered into the regression together with distributional variables (trainees’ gender and age, supervisors’ gender), and group characteristics (group size, and group gender composition).

In the first regression analysis, the overall model was significant and predicted $52 \%$ of the variance in the regression. $\mathrm{R}$ square $=.52 ; \underline{\mathrm{F}}(4,16)=4.324, p<.02$. The variables that were removed from the equation were the grouping variable (trainee/facilitator), training institution, trainee gender and age, supervisor gender, supervisory group size, EKARGS Relations with the supervisor, USGS Ideal use of the group, EKARGS Knowledge and skills attainment, SSQ Supportive style and SSQ Demanding style. As is shown in table 2, significant predictors were group gender composition (standardized beta= -.60, $\mathrm{p}<.01$ ), EKARGS Relationship with the supervision group (standardized beta $=.62, \mathrm{p}<.008$ ), USGS Actual use of the group (standardized beta= -.54, $\mathrm{p}<.02$ ) and SSQ Decisive style (standardized beta=.76, $\mathrm{p}<.002$ ).

Table 2 about here

The negative sign on the beta coefficient for group gender composition indicated that groups with both female and male supervisees were beneficial for perceived attainment of knowledge and skills. The variable USGS Actual use of the group also had a negative beta coefficient, which suggested that a strong focus on the group in the initial phase was not 
experienced as beneficial for learning at the final measurement. The positive beta coefficient for SSQ Decisive style suggested that a supervisor style that was perceived as more Decisive (consultative, directive, active, structured) at 6 months contributed to perceived attainment of psychotherapeutic knowledge and skills at the 18-month measurement.

The second simple regression analysis tested how much of the variance in the EKARGS: Knowledge and skills attainment scored at 18 months that was accounted for by 12 -month ratings. The same model was used as in the first regression analysis.

The second, overall model was significant and predicted $63 \%$ of the variance in the regression. $\mathrm{R}$ square $=.63 ; \underline{\mathrm{F}}(5,15)=5.079, p<.006$. The variables that were removed from the equation were the grouping variable (trainee/facilitator), training institution, trainee’s age and gender, supervisor's gender, supervisory group size, group gender composition, EKARGS Relations with the supervisor, USGS Ideal use of the group, and SSQ Supportive style.

Significant predictors in the second model were ratings at 12 months of EKARGS: Knowledge and skills attainment (standardized beta $=.64, \mathrm{p}<.01$ ), USGS Actual use of the group (standardized beta $=-.81, \mathrm{p}<.003$ ), SSQ Decisive style (standardized beta $=.65, \mathrm{p}<$ .004), and SSQ Demanding style (standardized beta= -..55, $\mathrm{p}<.01$ ). See table 3 .

Table 3 about here

The negative beta coefficient for the variable USGS Actual use of the group indicate that strong focus on the group at the second measurement was not profitable for the experience of perceived attained knowledge and skills (EKARGS: Knowledge and skills attainment) at the 18-month measurement.Supervisor styles that were perceived as more Decisive (SSQ Decisive style) but less Demanding (SSQ Demanding style) at 12 months were related to higher ratings on EKARGS: Knowledge and skills attainment at 18 months. 


\section{Discussion}

The findings in this study suggested that the trainees acquired a significant amount of the knowledge and skills that are essential for a psychotherapy supervisor. This result can be interpreted to mean that the supervisory course provided the trainees with relevant knowledge and training. However, this interpretation of the data could be questioned: Can the supervisor trainee be expected to have the capacity to make accurate evaluations of his or her own knowledge and competencies? If the answer to this question is no, a simple explanation of the finding could be that the higher self ratings that were presented in the final part of the training course, compared to the ratings presented in the initial part, resulted from an emerging consensus among the supervisory trainees that the training was effective.

For several decades the validity, accuracy, and importance of self-assessments have been discussed among physicians (Antonelli, 1997; Evans, McKenna, \& Oliver, 2002; Gordon, 1991), and attempts to assess self-evaluations empirically have been made (for a review, see Davis, Mazmanian, Fordis, Van Harrison, Thorpe et al., 2006). In their article, Belar and coworkers emphasized that the recent expansion of psychology's areas of practice to include clinical health psychology places the demand on psychologists "to develop the necessary expertise to provide quality services across a broader range of health problems” (Belar, Brown, Hersch, Hornyak, Rozensky et al., 2001, p. 136). In Belar et al.’s view, selfassessment and self-directed learning can provide a route to acquiring new knowledge and skills that, together with other forms of training, can guarantee the quality of care provided to patients. While some authors expressed enthusiasm (Johnson, 2003) and support (Seime, 2003) for this approach, others (e. g., Smith, 2003) were more doubtful about the usefulness of self-evaluation, especially for training in a complex area such as clinical health psychology.

It should be noted that the results in this study were based on data that were provided by both supervisor trainees and their facilitators and thus trainee self-evaluations of knowledge 
and skills attainment were complemented by supervisor evaluations. Given that the facilitators were highly trained psychotherapy supervisors with a profound work experience, it is reasonable to assume that they had the necessary expertise to rate their trainees' supervisory knowledge and skills. Although this fact, especially when considered together with the fact that the data set available for this study was small, does not give us grounds for ruling out the emerging consensus hypothesis, that explanation is rendered less plausible. Also, the fact that the difference between the two groups was insignificant at all the three measurement points yielded a tentative support of the usage of self-ratings in this study.

The regression analysis suggested that a number of variables that were measured in this study were related to perceived attainment of knowledge and skills necessary for a psychotherapy supervisor. The results of the two regression analyses were partly in line with our predictions; the results suggested that the relationship among trainees was a substantial predictor of attained knowledge. Surprisingly, this was not true for the relationship between trainee and supervisor, as measured with EKARGS. A second unexpected finding was that the regression suggested that there was no difference between trainees' and supervisors' views on what usage of the group, nor what supervisor style would be beneficial in different phases of the training. These findings need to be examined further using a bigger sample.

In line with our prediction, strong focus on group processes in the initial and middle phases of the training was negatively related to knowledge and skills attainment in the final phase of the training. This finding seems to mean that trainees and facilitators perceived that focus initially should be on the individual trainees ('authoritative supervision') rather than on the group ('co-operative supervision’). This is remindful of Inskipp and Proctor’s (1993) proposal, that a necessary basis for psychotherapy supervision is that a working alliance between a supervisor and a trainee is established during the initial phase of supervision. Thus, 
during this phase, the task is to develop firm relations with each in the group, and here the supervisor ideally uses a more authoritative style (Proctor \& Inskipp, 2001).

An alternative interpretation of the regression analysis is to consider the findings in terms of the trainees' reactions in a new learning situation. A modern definition of learning emphasizes the fact that the individual construes new knowledge on the basis of the knowledge that s/he already has (Bransford, Brown \& Cocking, 2000). This implies that prior knowledge must be restructured, and, during this process, the "previous knowledge may help or hinder the understanding of new information” (Bransford et al., 2000, p. 78). This also implies that new knowledge forces the learner to re-evaluate his or her experiences, knowledge, and skills. Bransford et al. cited numerous research studies where it is shown that learners need time not only to assimilate the new knowledge but also to integrate new information with the previous. In this perspective, the present findings could be taken to mean that, based on their previous experience, the supervisor trainees in this study may, at least initially, prefer to work in a dyadic relation in a group setting rather than in a co-operative, group supervisory relation. According to James and coworkers (James, Milne, Blackburn, \& Armstrong, 2006), the psychotherapy supervisor's task is to work with and expand each trainee's existing knowledge, beliefs, and skills in collaboration with the trainee. For example, in the supervisory course under study, it is the supervisor's task to decide whether the dyadic mode of supervision provides an optimal learning context. The facilitator "needs to recognize that successful supervision can be uncomfortable (e.g. challenging the supervisee’s preferred approach)” (James et al., 2006, p. 193) despite the facilitator’s attempts to find an optimal balance between working with knowledge that is familiar to the trainee and knowledge and skills that are yet unknown (e. g., work in Vygotsky's 'zone of proximal development'). From this perspective, the result of the regression analysis (a strong focus on group processes during the first half of the supervisory course had a negative relationship with knowledge attainment) 
could be taken to suggest that the average supervisor considered the supervision in the group mode to be optimal, given the trainees' experiences, knowledge and skills.

The regression analysis also resulted in some interesting relationships between supervisor style and knowledge attainment. The SSQ Decisive style (consultative, directive, active, structured) both at the 6-month and 12-month ratings had a positive relation to perceived attainment of knowledge and skills measured with the EKARGS at 18 months. A negative relationship was obtained between the SSQ Demanding style (confronting, critical, nonsupportive, and theoretical style) 12 month ratings and the EKARGS Knowledge and skills attainment ratings obtained at 18 months. Despite the fact that these findings may seem to contribute systematic and meaningful information about the supervisory process, it is important to bear in mind that the findings are derived from a pilot version of the SSQ, tried on a small sample of data. In consequence, no prediction was formulated for the relationship between supervisor style and supervisory knowledge and skills attainment, and no conclusion is drawn from these results. Nevertheless, these preliminary findings deserve some comments. First the findings seem to point in the same direction as a previous study of group supervision for beginning psychotherapists, where, in the trainees’ view, a stronger focus on theoretical issues tended to impede knowledge and skills acquisition (Ögren et al., 2005). Second, it should be pointed out that both these findings could be viewed from the constructivist learning theoretical perspective (Bransford et al., 2000): learning to become a psychotherapist, or a psychotherapy supervisor, is not always a comfortable experience (cf. Boalt Boëthius \& Ögren, 2000; Flavell, 1963; Greenhalgh, 2000; James et al., 2006; Ögren, Boalt Boëthius \& Sundin, in press; Szecsödy, 1990). Thus, the negative association between self-ratings of a theoretical style and knowledge attainment could be taken to suggest that the trainees experience the task to integrate supervisory practice with theoretical considerations to be extremely challenging and frustrating. Alternatively, the finding could indicate that a 
strong focus on theoretical issues is applied by the supervisor and his or her supervisees as a means to avoid emotional involvement in the supervisory relation, or to create distance to the client's intense emotional issues. From this perspective it becomes obvious that selecting “interventions and strategies that encourage rather than discourage trainees” in supervision (Barrett \& Barber, 2005, p. 169) is a complex task. Future research needs to examine how optimal learning in psychotherapy supervision in group is encouraged or hindered.

Some limitations of the present pilot study should be considered. No control group was available and therefore it is impossible to know if the same amount of knowledge and skills would have been obtained by supervisor trainees who did not undergo the type of training that the participants in this study did. The study design did not include an independent factor such as outcome data from the clients who were treated by the psychotherapists who received supervision from the trainees. Therefore, the validity of the self ratings used in this study is questionable. Attainment of knowledge and skills in supervision was self-reported and although trainee ratings were complemented by supervisor ratings, it cannot be ruled out that the supervisors' ratings were influenced by their participation in the training. However, the fact that the supervisors in this study were highly competent with many years of experience yields some support of the data. Furthermore, the trainees were adult learners who, despite the fact that they were in the beginning of their professional career as psychotherapy supervisors, in their work as psychotherapists they had had ample training in doing self evaluations. Although the study compared data from trainees and their facilitators from two different training programmes, these programmes were very similar, both in terms of training level, and amount and intensity of training provided. Therefore, this study does not yield information about the possible difference among programmes that provide different amounts of training. The self report instruments used in this study were ad hoc scales. The main reason for this choice was that the study examined psychotherapy supervision in group format, and although 
instruments for assessing individual supervision are available, few established instruments that measure group supervision are available. The scales that were used in this study had been tried in a number of studies of beginning psychotherapists before this study was done.

Another weakness is that the data only represent 21 supervisor trainees and 6 supervisors. Therefore, the results of statistical analyses performed should be considered as tentative, and do not allow for generalizations. The analysis of factors that might be predictive of perceived knowledge and skills used multiple regression analysis with backward elimination, which capitalizes on chance. However, the two predictions that were evaluated in the regression analyses were partly successful. Hence, it is safe to suggest that the study results are an important and promising start, with its focus “on supervision as it occurs in everyday, realworld settings” (Falender et al., 2004, p. 774).

To conclude, this pilot evaluation of a supervisory course seemed to suggest that the course provided a training that allowed trainees to attain knowledge and skills necessary for psychotherapy supervisors. The findings also emphasize the need of more research on learning in the context of group supervision in psychotherapy. Further studies should examine how supervisees learn during different stages of supervision, and what are optimal learning conditions. Another issue to explore is if this type of training can be presented to trainees, so that training would be provided in both sets of knowledge and skills together. Following Worthen and Lambert's (2007) recommendation, future research should relate systematically gathered information on client outcome to supervisory processes and activities. 


\section{Acknowledgement}

The authors would like to thank three anonymous reviewers for their valuable comments on an earlier version of the paper. We also wish to acknowledge the support and assistance of Gunnar Carlberg, PhD, the Erica Foundation, Stockholm, Björn Elwin, PhD and Raili Hultstrand, licensed psychologist, St. Lukas Training Unit, and the clinicians who participated in the study. Support for this research was provided by The Swedish Research Council, 7212002-2586 (to Marie-Louise Ögren). 


\section{References}

Antonelli, M. A. (1997). Accuracy of second-year medical students' self-assessment of clinical skills. Academic Medicine, 72, 563-565.

Barnett, R. (1998). Training the trainers: Is supervision inherent, caught or taught? In P. Clarkson (Ed.), Supervision. Psychoanalytic and Jungian perspectives (pp. 1-9). London, UK: Whurr Pubhishers, Ltd.

Barrett, M. S., \& Barber, J. P. (2005). A developmental approach to the supervision of therapists in training. Journal of Contemporary Psychotherapy, 35, 169-183.

Belar, C. D., Brown, R. A., Hersch, L. E., Hornyak, L. M., Rozensky, R. H., Sheridan, Sheridan, E. P., Brown, R. T., \& Reed, G. W. (2001). Self assessment in clinical health psychology: A model for ethical expansion of practice. Professional Psychology: Research and Practice, 32, 135-141.

Bernard, J. M. (1994). Reaction: On-campus training of doctoral-level supervisors. In J. E. Myers, (Ed.), Developing and directing counselor education laboratories (pp.141-144). Alexandria, VA, US: American Counseling Association.

Boalt Boëthius, S., \& Ögren, M-L. (2000). Role patterns in group supervision. Clinical Supervisor, 19, 45-70.

Boalt Boëthius, S., Sundin, E. C., \& Ögren, M-L. (2006). Group supervision from a small group perspective. Nordic Psychology, 58, 22-42.

Bransford, J. D., Brown, A. L., \& Cocking, R. R. (2000). How People Learn. Brain, mind, experience, and school. Washington, DC, US: National Academy Press.

Davis, D. A., Mazmanian. P. E., Fordis, M., Van Harrison, R., Thorpe, K. E., \& Perrier, L. (2006). Accuracy of physician self-assessment compared with observed measures of competence: a systematic review. Journal of the American Medical Association, 296, 10941102. 
Efstation, J. F, Patton, M. J., \& Kardash, C. M. (1990). Measuring the working alliance in counselor supervision. Journal of Counseling Psychology, 37, 322-329.

Ekstein, R., \& Wallerstein, R. S. (1972). The teaching and learning of psychotherapy (2nd ed.). New York, NY, US: International Universities Press.

Evans, A. W., McKenna, C., \& Oliver, M. (2002). Self-assessment in medical practice. Journal of the Royal Society of Medicine, 95, 511-513.

Falender, C. A., Cornish, J. A. E., Goodyear, R., Hatcher, R., Kaslow, N. J., Leventhal, G., Shafranske, E., Sigmon, S. T., Stoltenberg, C., \& Grus, C. (2004). Defining competencies in psychology supervision. A consensus statement. Journal of Clinical Psychology, 60, 771-785.

Flavell, J. H. (1963). The developmental psychology of Jean Piaget. New Jersey:, NJ, US: Van Nostrand Company, Inc.

Frayn, D. H. (1991). Supervising the supervisors: the evolution of a psychotherapy supervisors’ group. American Journal of Psychotherapy, 45, 31-42.

Friedlander, M. L., \& Ward, L. G. (1984). Development and validation of the Supervisory Styles Inventory. Journal of Counseling Psychology, 31, 541-557.

Gordon, M. J. (1991). A review of the validity and accuracy of self-assessments in health professions training. Academic Medicine, 66, 762-769.

Greenhalgh, P. (2000). Emotional growth and learning. London, UK: Routledge.

Herbert, J. T., Ward, T. J., \& Hemlick, L. M. (1995). Confirmatory factor analysis of the Supervisory Style Inventory and the Revised Supervision Questionnaire. Rehabilitation Counseling Bulletin, 38, 334-349.

Holloway, E. L., \& Neufeldt, S. A. (1995). Supervision: It’s contribution to treatment efficacy. Journal of Consulting \& Clinical Psychology, 63, 207-213. 
Inskipp, F., \& Proctor, B. (1993). The art, craft and tasks of counselling supervision. Part 1. Making the most of supervision. Twickenham, UK: Cascade.

Jakubowski-Spector, P., Dustin, R., \& George, R. L. (1971). Toward developing a behavioral counselor education model. Counselor Education and Supervision, 10, 242-250.

James, I. A., Milne, D., Blackburn, I. M., \& Armstrong, P. (2006). Conducting successful supervision: Novel elements towards an integrative approach. Behavioural and Cognitive Psychotherapy, 35, 191-200.

Jansson, V. (1975). Psykoterapihandledningens pedagogic (Teaching methods in psychotherapy supervision). Lakartidningen, 79, 213-218.

Johnson, N. G. (Nov 2003). A step in the right direction: Comment on Belar et al. (2001). Prevention \& Treatment. 6(1). Available at http://content.apa.org/journals/pre/6/1/28c.html Ladany, N., \& Lehrman-Waterman, D. E. (1999). The content and frequency of supervisor self-disclosures and their relationship to supervisor style and the supervisory working alliance. Counselor Education \& Supervision, 38, 143-160.

Ladany, N., Walker, J., \& Melincoff, D. S. (2001). Supervisory style: its relation to the supervisory working alliance, and supervisor self-disclosures. Counselor Education and Supervision, 40, 263-275.

Linehan, M. M. (1980). Supervision of behavior therapy. In A. K. Hess (Eds.), Psychotherapy supervision: Theory, research and practice (pp. 48-180). New York, NY, US: John Wiley. Milne, D. L., \& James, I. A. (2002). The observed impact of training on competence in clinical supervision. British Journal of Clinical Psychology, 41, 55-72.

Neufeldt, S. A. (1994). Use of a manual to train supervisors. Counselor Education and Supervision, 33, 327- 336.

Ögren, M-L., Boalt Boëthius, S., \& Sundin, E. (in press). The significance of group format and supervisors' function as role models in psychotherapy supervision. Nordic Psychology. 
Ögren, M-L., \& Jonsson C-O. (2003). Psychotherapeutic skill following group supervision according to supervisees and supervisors. Clinical Supervisor, 22, 35-58.

Ögren, M-L., Jonsson, C-O., \& Sundin, E. C. (2005). Group supervision in psychotherapy. The relationship between focus, group climate, and perceived attained skill. Journal of Clinical Psychology, 61, 373-388.

Ögren, M-L \& Sundin, E. C. (2004). Grupphandledning i psykoterapi inom utbildningsramar. Presentation av ett pågående forskningsprojekt, samt preliminära resultat från en delstudie. [Group supervision in psychotherapy. Preliminary findings from an ongoing research project]. Matrix, 1, 60-73.

Ögren, M-L \& Sundin, E. C. (2005). Intervjuer som prognosinstrument för studieframgång. [Interviews as a prognostic instrument for study success]. Nordisk Psykologi, 3, 271-288. Ögren, M-L \& Sundin, E. C. (2007). Experiences of the group format in psychotherapy supervision. Clinical Supervisor, 25, 1/2, 69-82.

Prieto, L.R. (1996). Group supervision: still widely practiced but poorly understood. Counselor Education and Supervision, 35, 295-307.

Proctor, B., \& Inskipp, F. (2001). In J. Scaife (Ed.), Supervision in mental health professions. A practitioner's guide (pp. 99-121). London, UK: Brunner-Routledge.

Rice, L. N. (1980). A client-centered approach to the supervision of psychotherapy. In A. K. Hess (Ed.), Psychotherapy supervision: Theory, research, and practice (pp. 136-147). New York, NY, US: John Wiley \& Sons.

Russell, R. K., \& Petrie, T. (1994). Issues in training effective supervisors. Applied and Preventive Psychology, 3, 27-42.

Seime, R.J. (Nov 2003). Self-assessment in clinical psychology: Is the model sufficient for expansion of practice in clinical health psychology? Comment on Belar et al. (2001). 
Prevention and Treatment, 6, Article 27. Available at

http://content.apa.org/journals/pre/6/1/27c.html

Smith, T. W. (Nov 2003). On being careful when you get what you wish for: Comment on Belar et al. (2001). Prevention \& Treatment. 6(1). Available at http://content.apa.org/journals/pre/6/1/26c.html

Sternberg, R. J., \& the Rainbow Project Collaborators. (2006). The Rainbow Project: Enhancing the SAT through assessments of analytical, practical, and creative skills. Intelligence, 34, 321-350.

Steward, R. J., Breland, A., \& Neil, D. M. (2001). Novice supervisees’ self-evaluations and their perceptions of supervisor style. Counselor Education and Supervision, 41, 131-141.

Sundin, E., \& Ögren, M-L. (2006). Implications of an individualized admission selection procedure for professional programs in psychology. Learning in Health and Social Care, $16,226-240$.

Szecsödy, I. (1990). The learning process in psychotherapy supervision. Department of Psychiatry, Karolinska Institutet, Sankt Göran Hospital, Stockholm, Sweden.

Usher, C-H., \& Borders, L. D. (1993). Practicing counselors' preferences for supervisory style and supervisory emphasis. Counselor Education and Supervision, 33, 66-79.

Watkins, C. E., Jr. (1998). Psychotherapy supervision in the 21st century: Some pressing needs and impressing possibilities. Journal of Psychotherapy Practice and Research, 7, 93-101.

Whitman, S. M., Ryan, B., \& Rubenstein, D. F. (2001). Psychotherapy supervisor training. Differences between psychiatry and other mental health disciplines. Academic Psychiatry, 25, 156-161. 
Worthen, V. \& Lambert, M. J. (2007). Outcome oriented supervision: Advantages of adding systematic client tracking to supportive consultations. Counselling \& Psychotherapy Research, 7, 48-53.

Worthington, E. L. Jr. (1987). Changes in supervision as counsellors and supervisors gain experience: A review. Professional Psychology: Research and Practice, 18, 189-208. 
Table 1. Perceived attainment of supervisory knowledge and skills

\begin{tabular}{lccccc}
\hline & & & 6 months & 12 months & 18 months \\
Variables & Category & $\mathrm{N}$ & $\mathrm{M}(\mathrm{SD})$ & $\mathrm{M}(\mathrm{SD})$ & $\mathrm{M}(\mathrm{SD})$ \\
\hline $\begin{array}{l}\text { Knowledge and } \\
\text { skills attainment }\end{array}$ & $1^{1}$ & 21 & $3.37(.60)$ & $3.80(.45)$ & $4.02(.41)$ \\
& $2^{2}$ & 6 & $3.50(.68)$ & $3.85(.49)$ & $4.13(.98)$
\end{tabular}

Note. ${ }^{1}=$ supervisor trainees; ${ }^{2}=$ supervisors 
Table 2. Simple regression analysis: Relationship between 6-month predictors and perceived outcome

Outcome variable:

EKARGS: Knowledge and skills attainment (18 months)

\begin{tabular}{lll}
\hline Predictor Variables & $\mathrm{B}$ & $\mathrm{F}$ \\
\hline Group gender composition & $-.60^{* *}$ & 2.897 \\
EKARGS Relationship with the supervision group & $.62^{* *}$ & 3.001 \\
(6 months) & & \\
USGS Actual use of the group (6 months) & $-.54^{*}$ & 2.612 \\
SSQ Decisive style (6 months) & $.76^{* *}$ & 3.666 \\
\hline
\end{tabular}

${ }^{*} \mathrm{p}=.05,{ }^{* *} \mathrm{p}=.01, * * * \mathrm{p}=.001$ 
Table 3. Simple regression analysis: Relationship between 12-month predictors and perceived outcome

Outcome variable:

EKARGS: Knowledge and skills

attainment (18 months)

\begin{tabular}{lll}
\hline Predictor Variables & $\mathrm{B}$ & $\mathrm{F}$ \\
\hline USGS Actual use of the group (12 months) & $-.81^{* *}$ & 3.543 \\
SSQ Decisive style (12 months) & $.65^{* *}$ & 3.425 \\
EKARGS Knowledge and skills attainment & $.64^{* *}$ & 2.789 \\
(12 months) & & \\
SSQ Demanding style (12 months) & $-.55^{* *}$ & 2.842 \\
EKARGS Relationship with the supervision group & $.36^{*}$ & 1.959 \\
(12 months) & &
\end{tabular}

${ }^{*} \mathrm{p}=.05, * * \mathrm{p}=.01, * * * \mathrm{p}=.001$ 